\title{
Eptastigmine led to cognitive, clinical, and functional benefits in Alzheimer's disease
}

Imbimbo BP, Martelli P, Troetel WM, et al, and the Eptastigmine Study Group. Efficacy and safety of eptastigmine for the treatment of patients with Alzheimer's disease. Neurology 1999 Mar 10;52:700-8.

\section{Question}

In patients with moderate to moderately severe Alzheimer's disease $(\mathrm{AD})$, how effective and safe is eptastigmine?

\section{Design}

Randomised, double blind, placebo controlled trial with 24 weeks of follow up.

\section{Setting}

36 centres in the US and Europe.

\section{Patients}

491 patients (mean age $71 \mathrm{y}, 63 \%$ women) who met the diagnostic criteria for AD established by the NINCDS-ADRDA and described by $D S M-I V$, and who had a cognitive deficit for $\geq 6$ months, a MiniMental State Examination Scale score between 10 and 22, a Global Deterioration Scale rating of 4 or 5 , a modified Hachinski ischaemic score $<3$, and a Hamilton Depression Scale score $<18$. Exclusion criteria were other neurological or psychiatric disorders; renal, hepatic, or cardiovascular diseases; peptic ulcer; bronchial asthma; neutropenia; deficiencies in thyroxine, vitamin $\mathbf{B}_{12}$, or folate; or treatment with medication known to affect the central nervous system. $86 \%$ completed the study.

\section{Intervention}

164 patients were assigned to placebo, 166 to $15 \mathrm{mg} 3$ times daily of eptastigmine, and 161 to $20 \mathrm{mg} 3$ times daily of eptastigmine for a period of 24 weeks. Eptastigmine was given using a 4 week stepwise dose escalation starting from $5 \mathrm{mg} 3$ times daily.

\section{Main outcome measures}

Changes in cognition (Alzheimer's Disease Assessment Cognitive Subscale [ADAS-Cog]), global function (Clinician's InterviewBased Impression of Change Plus [CIBIC-Plus]), and activities of daily living (Instrumental Activities of Daily Living Scale [IADL]).

\section{Main results}

Data for 463 patients were included in the analysis with the last outcome carried forward for 15 . The table shows the mean change from baseline to week 24 on the ADAS-Cog, CIBIC-Plus, and IADL. $48 \%$ of patients in the higher dose group had adverse effects compared with 54\% in the lower dose group and $49 \%$ in the placebo group. There was a dose dependent transient and mild neutropenic effect associated with eptastigmine treatment.

\section{Conclusion}

$20 \mathrm{mg} 3$ times daily of eptastigmine led to cognitive, clinical, and functional benefits in patients with moderate to moderately severe Alzheimer's disease but with increased risk of adverse haematological effects.

\begin{tabular}{|c|c|c|c|}
\hline Scale & Placebo & $15 \mathrm{mg}$ & $20 \mathrm{mg}$ \\
\hline ADAS-Cog & \multirow{3}{*}{2.6} & & \\
\hline Mean change & & 1.1 & 0.4 \\
\hline $\begin{array}{l}\text { Drug-placebo adjusted } \\
\text { difference }(95 \% \mathrm{CI})\end{array}$ & & $1.6(0.1$ to 3.2$)$ & $2.3(0.7$ to 3.8$)$ \\
\hline CIBIC-Plus & \multirow{3}{*}{4.4} & & \\
\hline Mean change & & 4.2 & 4.0 \\
\hline $\begin{array}{l}\text { Drug-placebo adjusted } \\
\text { difference }(95 \% \mathrm{CI}) \\
\text { IADL }\end{array}$ & & $0.1(-0.1 \text { to } 0.3)^{*}$ & $0.3(0.1$ to 0.5$)$ \\
\hline Mean change & \multirow[t]{2}{*}{1.2} & 0.8 & 0.6 \\
\hline $\begin{array}{l}\text { Drug-placebo adjusted } \\
\text { difference }(95 \% \mathrm{CI})\end{array}$ & & $0.4(-0.1 \text { to } 0.9)^{*}$ & 0.7 (0.2 to 1.2$)$ \\
\hline
\end{tabular}

*Not significant. $\mathrm{AD}=$ Alzheimer's Disease; $\mathrm{ADAS}-\mathrm{Cog}=$ Alzheimer's Disease Assessment Cognitive Subscale; CIBIC-Plus = Clinician's Interview-Based Impression of Change Plus; IADL = Instrumental Activites of Daily Living Scale.

Source of funding: not stated.

For correspondence:Dr B P Imbimbo, Medical Department, Mediolanum Farmaceutici, via Cottolengo 15,20143 Milan, Italy. Fax +39289132375.

\section{Commentary}

The cholinergic hypothesis of memory loss has to contend with the glutamatergic hypothesis of amnesia and dementia. ${ }^{1}$ These studies by Imbimbo et al and Winblad and Poritis are based on these alternative approaches.

Acetylcholinesterase inhibitors (AChEIs) have been the most widely investigated drugs in mild to moderate $\mathrm{AD}$. Measures of their efficacy should tap 4 areas: cognition, functional activity, noncognitive behaviours, and independent ratings of global change. Compared with placebo, the AChEIs tacrine, donepezil, metrifonate, and rivastigmine show a modest improvement of cognitive function of 2-4 ADAS-Cog points over 6 months, with a return then to baseline values or less. ${ }^{2}$ Ratings of global impression of change improve $1 / 3-1 / 2$ point.
Non-cognitive dysfunction has rarely been studied, and improvements in activities of daily living (ADL) have been hard to detect, except for rivastigmine. ${ }^{3}$ Overall, up to one quarter of patients do well on AChEIs, but the majority see little to no benefit. Which quarter improves, we cannot predict. The decrease in burden of care has been studied less.

The study by Imbimbo $e t a l$ is well designed and was done with a low dropout rate. Unfortunately, the magnitude of the cognitive benefit was in the lower half of the range reported for other AChEIs and the number with the change normally considered clinically significant $(\geqslant 4$ ADAS-Cog points) is not reported. But eptastigmine joins rivastigmine in showing substantial benefit on ADL. The dose response effect and the consistency of modest improvements in cognition and daily functioning support the clinical relevance of the results. Although the cholinergic tolerability of eptastigmine was favourable, $4.5 \%$ of patients developed a mild transient neutropenia, which was dose dependent and included 1 case of severe neutropenia in the eptastigmine $20 \mathrm{mg}$ group (3 times daily). It is surprising that patients with neutropenia continued in the trial and that there is no comment on incident infections. Another patient on eptastigmine, $20 \mathrm{mg}$ (3 times daily), however, developed aplastic anaemia, a risk of $0.3 \%$ (95\% CI $0.01 \%$ to $1.7 \%$ ), whereas the risk in the general population is 2 per million per year. The risk on eptastigmine, similar to that of clozapine, will probably limit the use of the (commentary continued on page 113) 


\title{
Memantine led to functional improvement and reduced care dependence in severe dementia
}

\author{
Winblad B, Poritis N.Memantine in severe dementia: results of the ${ }^{9} m$-best study (benefit and efficacy in severely demented patients \\ during treatment with memantine). Int J Geriat Psychiatry 1999 Feb;14:135-46.
}

\section{Question}

In patients with moderately severe to severe primary dementia, how effective and safe is memantine?

\section{Design}

Randomised, double blind, placebo controlled trial with 12 weeks follow up.

\section{Setting}

7 trial centres in Latvia.

\section{Patients}

167 care dependent inpatients with moderately severe to severe dementia defined by DSM-III-R criteria (49\% Alzheimer's disease, $51 \%$ vascular dementia) and with severity assessed by the Global Deterioration Scale (stages 5-7) and the Mini-Mental State Examination ( $<10$ points). Exclusion criteria included duration of dementia $<12$ months; central nervous system active drugs within the previous 14 days; severe, chronic, or terminal diseases; impaired thyroid function, lowered $\mathrm{B}_{12}$ blood concentration; abnormal blood chemistry; alcoholism or drug addiction; major depression; learning disability; epilepsy; and Parkinson's disease. 1 patient was excluded from the analysis.

\section{Intervention}

82 patients were assigned to memantine $(5 \mathrm{mg}$ /d during the first week and $10 \mathrm{mg} / \mathrm{d}$ during the next $11 \mathrm{wks}$ ) and 84 to placebo.

\section{Main outcome measures}

Clinical Global Impression of Change (CGI-C) rated by the physician, and the Behavioural Rating Scale for Geriatric Patients (BGP), subscore "care dependence," rated by the nursing staff.

\section{Main results}

At 12 weeks, more patients receiving memantine had a positive treatment response (defined as 3 categories of improvement on the CGI-C) than those receiving placebo $(\mathrm{p}<0.001)$ (table). There was a 3.1 point improvement on the BGP subscore "care dependence" for those in the memantine group compared with a 1.1 point improvement for those in the placebo group $(p=0.016)$. A coincidental response of 3 categories of improvement on the CGI-C and an improvement of $\geq 15 \%$ on the BCG subscore was observed in more patients receiving memantine than those receiving placebo $(\mathrm{n}=151)$ (table).

\section{Conclusion}

Memantine led to functional improvement and reduced care dependence in patients with severe dementia.

Memantine v placebo at 12 weeks in severe dementia*

\begin{tabular}{lllll}
\hline Outcomes & Memantine Placebo & RBI $(95 \%$ CI $)$ & NNT (CI) \\
\hline $\begin{array}{l}\text { Treatment response on the } \\
\text { CGI-C }\end{array}$ & $73 \%$ & $45 \%$ & $62 \%(25$ to 114$)$ & $4(3$ to 8$)$ \\
$\begin{array}{c}\text { Coincidental response on the } \\
\text { CGI-C and BGP subscore }\end{array}$ & $61 \%$ & $32 \%$ & $94 \%(35$ to 186$)$ & $4(3$ to 8$)$
\end{tabular}

*CGI-C = Clinical Global Impression of Change; BGP = Behavioural Rating Scale for Geriatric Patients. Other abbreviations defined in glossary; RBI, NNT, and CI calculated from data in article.

\section{Source of funding: not stated.}

For correspondence: Dr B Winblad, Karolinska Institutet, Department of Clinical Neuroscience and Family Medicine, Division of Geriatric Medicine, B 84, Huddinge University Hospital, 14186 Huddinge, Sweden. Fax +46858585470 . (commentary continued from page 112) drug, certainly if there is no blood monitoring and with safer alternative drugs available. Patient or carer convenience was also less with thrice daily medication compared with rivastigmine's twice and donepezil's once daily regimens.

Severe dementia imposes a great challenge to carers. Functional and global clinical endpoints are more relevant here than cognitive ones. Memantine is an N-methylD-aspartate antagonist, which blocks the exitotoxic effects of excess glutamate release, considered central to memory and behavioural dysfunction and to the pathology of $\mathrm{AD}$ and vascular dementia. ${ }^{1}$ The results of the memantine study by Winblad and Poritis appear to be unbiased. The coincidence of treatment effects in independent nursing and medical assessments supports the validity and clinical significance of the results, but the design allowed no examination for dose response effect
The reported benefits and tolerability need to be established in a much longer duration trial, with health economic analysis. Adverse effects (not described) and serious adverse effects (mainly cardiac deaths) were equivalent in the 2 groups. Memantine seems useful not only in severe $\mathrm{AD}$ but also in vascular and mixed dementias, and in those without substantive behavioural problems (neuroleptics, hypnotics, and some antidepressants were excluded in trial patients), found in approximately $40 \%$ of patients with $\mathrm{AD}$. Although glutamate antagonists may induce transient psychoses, memantine is thought not to do so.

These 2 contrasting pharmacological approaches to $\mathrm{AD}$, here studied at different levels of severity, leave key issues unanswered: who benefits? Is response genotype specific? How substainable and valuable is a 2 point drop in carer dependence (memantine) in progressive dementia? Are there longer term side effects? Are skills regain- able without rehabilitation? And how do the modest gains translate into quality adjusted life years and reduce burden of care and costs? In the future, non-cognitive symptoms should be assessed because they increase disease progression and disability, predict high family burden and costs, and are the primary cause of institutionalisation. ${ }^{1}$ Memantine's possible advantage of neuroprotection suggests that treatment combinations with AChEIs might enhance the benefits of only 1 approach.

Robin Jacobson,

MD, MRCP (UK), FRCPsych St George's Hospital Medical School London, UK

1 Cacabelos R, Takeda M, Winblad B. The glutamatergic system and neurodegeneration in dementia: preventive strategies in Alzheimer's disease. Int J Geriatr Psychiatry 1999:14.9-47.

2 Allen H. Anti-dementia drugs. Int J Geriatr Psychiatry 1999:14:239-43.

chiatry 1999;14:239-43. osler M, Anand R, Cicin-Sain A, et al. Efficacy and safety of rivastigmine in patients with Alzheimer's disease: international randomised controlled trial. BMJ 1999;318:633-8. 